\title{
CHLORINATION OF KETONES WITH SELENIUM OXYCHLORIDE
}

$$
\text { by }
$$

Fred Max Sonnenberg

A Thesis Submitted to the Faculty of the DEPARTMENT OF CHEMISTRY

In Partial Fulfillment of the Requirements For the Degree of MASTER OF SCIENCE

In the Graduate College

THE UNIVERSITY OF ARIZONA 


\title{
STATEMENT BY AUTHOR
}

This thesis has been submitted in partial fulfillment of requirements for an advanced degree at The University of Arizona and is deposited in the University Library to be made available to borrowers under rules of the Library.

Brief quotations from this thesis are allowable without special permission, provided that accurate acknowledgment of source is made. Requests for permission for extended quotation from or reproduction of this manuscript in whole or in part may be granted by the head of the major department or the Dean of the Graduate College when in their judgment the proposed use of the material is in the interests of scholarship. In all other instances, however, permission must be obtained from the author.

\section{SIGNED: Tred Max Sommerg}

\author{
APPROVAL BY THES IS DIRECTOR
}

This thesis has been approved on the date shown below:

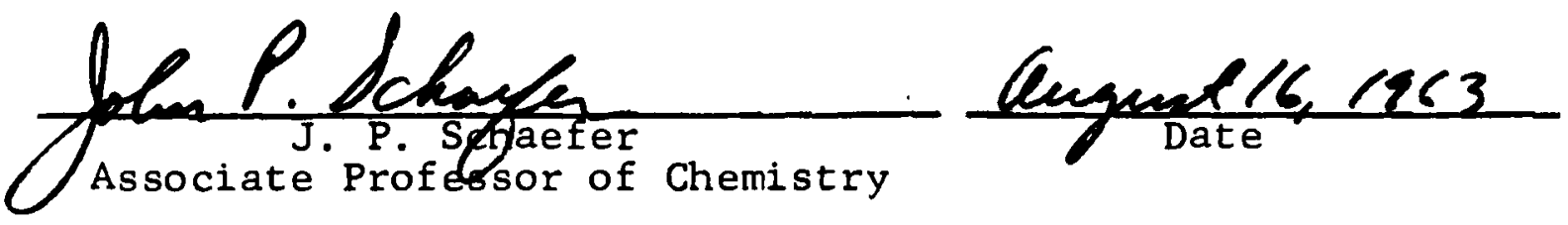




\section{ACKNOWLEDGMENT}

The author wishes to express his gratitude and appreciation to Dr. John P. Schaefer for his guidance, assistance, and encouragment throughout the course of this work. Indebtedness is also due to Dr. Joseph Sonnenberg for the intial formation of this manuscript and to Miss Judy L. Adelstone for proofreading. In addition, the author expresses:his thankfulness to the Selenium and Tellurium Development Committee for the supporting funds. 
TABLE OF CONTENTS

Page LIST OF TABLES . . . . . . . . . . . . . . . . . . . . vi vi v ABSTRACT ...................... . . vii PREPARATION AND PROPERTIES . .................. . . . 1

1... Selenium Oxychloride .. . ................. 1

2... Selenium Oxybromide . . . . . . . . . . 2

3. Selenium Tetrachloride . . . . . . . . . . 3

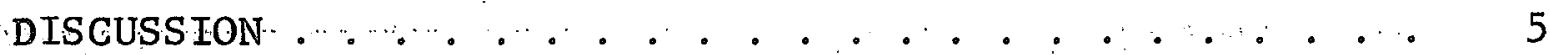

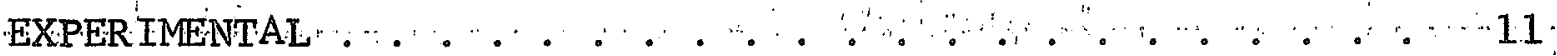

1. Selenium Oxychloride Chlorinations $\ldots \cdots, \ldots, \cdots, \cdots 11$ a." Selenium Oxychloride $\ldots, \ldots, \cdots, \cdots, \cdots, \cdots, 11$

b. Dichloroselenoacetophenone . ........ . . 11

c. a-Chloroacetophenone............. 12

d. . p-Bromo- $\alpha$-ch1oroacetophenone....... . 14

e. p-Methoxy- $\alpha$-chloroacetophenone ...... 15

f. p-Methyl- $\alpha$-chlorøacetophenone . . . . . . 15

g. $\alpha$-Chloropropiophenone .................. 16

h. 3,3-Dimethy1-1-ch1oro-2-butanone ..... 16

i.. Chloroacetone ... . ............. 17

j. 3-Chloro-2-butanone ................ 17

k. 2-Chlorocyclohexanone .......... 18 
2. Selenium Oxybromide Brominations . . . . . . . 22

a. Selenium Oxybromide .......... 22

b. $a$-Bromoacetophenone . . . . . . . . . 22

c. 3,3-Dimethy 1-1-bromo-2-butanone ...... 23

d. 2-Bromocyclohexanone . . . . . . . . . 24

3. Selenium Tetrachloride Chlorination . . . . . . 24

a. Selenium Tetrachloride... . . . . . . 24

b. Dichloroselenoacetophenone .. . . . . . 25

c. $\alpha$-Chloroacetophenone . . . . . . . . 25

4. Sodium Borohydride Reductions . . . . . . . . 25

a. a-Phenylethanol (from acetophenone) . . . 25

b. $\alpha$-Phenylethanol (from dichloroselenoacetophenone ............... . 26

c. p-Bromopheny $1-\alpha-$ ethanol . . . . . . . 27

d. p-Methoxyphenyl-a-ethanol ........ 27

e. p-Methylpheny $1-\alpha-$ ethano1 . . . . . . . 27

f. Rate Study . . . . . . . . . . . 28

5. Mì scellaneous ............. . . 29

a. Acetophenone . . . . . . . . . . . . 29

BIBLIOGRAPHY . . . . . . . . . . . . . . 30 


\section{LIST OF TABLES}

Table Page

I. Percentage Yields . . . . . . . . . . 6

II. Observed Infrared Maxima for the Carbonyl . . 8

III. Observed Ultraviolet Spectral Data for the

Carbony 1 : . . . ........... . .. . 9

IV. Preparational Data and Melting Points . .... 21 


\section{ABSTRACT}

A new method of synthesizing a-haloketones was developed by reacting selenium oxychloride or selenium oxybromide with ketones possessing an active methylene group. The rate of formation of the dichloroselenoketone is aided by an electron-donating group in the para position of the benzene ring while hindered by an electronwithdrawing group in the para position. The decomposition of the dichloroselenoketone leads to the $\alpha$-chloroketone. The use of selenium oxybromide leads directly to the $\alpha$-bromoketone without isolation of a dibromoselenoketone. 


\section{PREPARATION AND PROPERTIES}

\section{Selenium Oxychloride}

Selenium oxychloride, $\mathrm{SeOC}_{2}$, was first synthesized in 1859 by Weber, ${ }^{1}$ who brought together the vapors of sele-th. nium tetnachloride and selenium dioxide. In 1887. Michaëlis ${ }^{2}$ prepared selenium oxychloride by the interaction of phosphorus pentachloride upon selenium dioxide. A short time later Cameron and Macallan 3 allowed a mixture of selenium dioxide and sodium chloride to interact and obtained sodium selenite and selenium oxychloride.

The research of Lenker ${ }^{4}$ during the early $1920^{\circ} \mathrm{s}$ led to three different methods of preparing selenium oxychloride. They are as follows: direct union of selenium tetrachloride and selenium dioxide at room temperature; partial hydrolysis of selenium tetrachloride; and dehydration of dichloroselehious acid, $\mathrm{SeO}_{2} \cdot 2 \mathrm{HC} 1$. A laboratory preparation based on the ideas of Lenher is found in "Inorganic Synthesis." 5

The physical properties of selenium oxychloride have been investigated by Lenher $6,7,8,9$ Selenium oxychloride is a pale yellow liquid that boils at $176.4^{\circ}$ at $726 \mathrm{~mm}$., melts at $8.5^{\circ}, \mathrm{D}_{4}^{22} 2.424$, and $\mathrm{n}_{\mathrm{D}}^{20} 1.6516$. In moist air selenium oxychloride fumes, liberating hydrochloric acid. Near the 
boiling point under atmospheric conditions selenium oxychloride partially decomposes forming selenium dioxide, selenium tetrachloride, and selenium. Selenium oxychloride is miscible in al1 proportions forming physical mixtures with benzene, carbon disulfide, carbon tetrachloride, and chloroform. When 0.005 ml. of selenium oxychloride is applied to the skin of a man, 10 a third degree burn is produced which takes nearly 30 days to hea.1.

The chemical properties of selenium oxychloride were first examined by Lenher 6,7 who investigated the action upon naturally occurring materials such as wood, leather, resins, carbohydrates, proteins, etc., in addition to most inorganic elements and compounds. He noted that selenium oxychloride is a very powerful oxidizing and chlorinating agent. The chemical action of selenium oxychloride upon alcohols, 11,12 tertiary aromatic amines, $13,14,15$ esters, ${ }^{16}$ ethers, 17,18 Grignard's reagent, ${ }^{19}$ ketones ${ }^{20,21,22}$ olefins, 6, 23,24,25 and phenols $18,26,27$ has been described in the literature. With ketones, selenium tetrachloride ${ }^{18,26,28,29}$ forms the same selenium adduct as does selenium oxychloride.

\section{Se Lenium Oxybromide}

Selenium oxybromide, $\mathrm{SeOBr}_{2}$, was first synthesized in 1866 by Schneider, ${ }^{30}$ who reacted selenium dioxide with selenium tetrabromide. In 1913 Glauser $^{31}$ prepared selenium 
oxybromide by allowing sodium bromide to interact with sele-..: nium oxyckløride. Lenher, ${ }^{32}$ in 1922, modified Schneider's method by mixing selenium with selenium dioxide and then adding bromine. Just recent 1 y $\mathrm{K}$ likorka ${ }^{33}$ prepared selenium oxybromide by treating aluminum bromide with selenium oxychloride.

Lenher ${ }^{32}$ has described the physical and chemical properties of selenium oxybromide. It is a reddish-yellow solid that melts at $41,6^{\circ}$ and boils at $216^{\circ}$ at $740 \mathrm{~mm}$. with considerable decomposition. Selenium oxybromide is readily soluble in benzene, carbon disulfide, chloroform, toluene, and xylene. The chemical properties are very similar to those of selenium oxychloride.

\section{Selenium Tetrachloride}

In 1818 Berzelius ${ }^{34}$ passed the vapors of chlorine over elemental selenium which is converted to diselenium dichloride, $\mathrm{Se}_{2} \mathrm{Cl}_{2}$, which then combines with more chlorine to form selenium tetrachloride, $\mathrm{SeCl}_{4^{\circ}}$. Michaelis, 35,36 in 1871, reacted selenium oxychloride with phosphorus oxychloride or selenium with thionyl chloride to prepare selenium tetram chloride. A short time later Clausnizer ${ }^{37,38}$ interacted selenium with sulfuryl chloride or selenium oxychloride with sulfuryl chloride to synthesize selenium tetrachloride. Lenher and North ${ }^{39}$ prepared selenium tetrachloride in 1907 using selenium oxychloride and thionyl chloride. 
Selenium tetrachloride is a bright yellow crystalline solid that sublimes at $196 \pm 1^{\circ}$ and melts at $305 \pm 30^{\circ} 40$ From 109 to $226^{\circ}, 41$ the vapors from selenium tetrachloride consist entirely of selenium dichloride, $\mathrm{SeCl}_{2}$, and chlorine. Selenium tetrachloride is slightly soluble in a1cohol, carbon tetrachloride, chloroform, and ether.

Selenium tetrachloride reacts with many elements and inørganic compounds. The chemical action of selenium tetrachloride upon acids, 42,43 amines, $14,44,45$ esters, 43 Grignard's reagent ${ }^{46}$ ketones, $18,26,28,29,47,48,49$ and olefins $50,51,52,53,54$ has been described in the literature. 


\section{DISCUSS ION}

A new method for synthesizing $\alpha$-halo ketones in yields of 24-63\% (Table I) was developed by reacting selenium oxychloride or selenium oxybromide with ketones possessing an active methylene group. The general reactions can be represented by the following equations:<smiles>[R2]C(C)=O</smiles>

It was possible using selenium oxychloride to isolate the dichloroselenoketone in yields of $43-87 \%$ (Table I). with each ketone except methyl ethyl ketone. The solid selenium adduct usually remains stable from one to two weeks with the exception of those formed from acetone and cyclohexanone wich start to decompose shortly after formation. When the dichloroselenoketone is decomposed by heating with a free flame or warming slowly in a mineral oil bath, hydrochloric acid is evolved below the melting point. After purification, 
TABLE I

PERCENTAGE YIELDS

\begin{tabular}{|c|c|c|c|}
\hline & Dichloroseleno- & Selenium & $\alpha-$ Chloro- \\
\hline Acetophenone & $57.8-79.4$ & $89.1-96.0$ & $33 \cdot 6-49 \cdot 5$ \\
\hline p-Bromoacetophenone & $42.9-46.8$ & 40.2 & 38.6 \\
\hline p-Methoxyacetophenone & $63.8-86.5$ & 97.7 & 40.6 \\
\hline p-Methylacetophenone & 69.3 & 93.6 & 38.7 \\
\hline Propiophenone & $46.4-52.3$ & $81.3-81.8$ & $25.6-41.6$ \\
\hline Methyl t-buty 1 ketone & 69.4 & 69.6 & 45.7 \\
\hline Acetone & 82.7 & $71.8-86.2$ & $24.1-37.1$ \\
\hline Methyl ethyl ketone & $-\infty$ & 88.2 & $29.8-34.5$ \\
\hline \multirow[t]{2}{*}{ Cyclohexanone } & $-\infty$ & 91.3 & $39.1-40.8$ \\
\hline & Dibromoseleno- & Selenium & $\alpha-B r o m o-$ \\
\hline Acetophenone & $-\infty$ & $-\infty$ & $48.7-62.7$ \\
\hline Methyl t-buty 1 ketone & $-\infty$ & $-\infty$ & 46.1 \\
\hline Cyclohexanone & -- & $-\ldots$ & 30.8 \\
\hline
\end{tabular}


a vacuum distillation of the residue leads to $a$-chloroketone, a small amount of the starting ketone, and a fair amount of tar.

The observed infrared and ultraviolet spectrum of the carbonyl for the various ketones, $\alpha$-chloroketones, and dichloroselenoketones are listed on page 8 and 9, respectively.

In order to determine the relative effects of groups substituted in the para position of the benzene ring, a rate study wias performed in which each ketone was mixed in equimolar quantities with acetophenone, which was in 10 mole excess of the selenium oxychloride used. The dichoroselenoketone was reduced by sodium borohydride to the a-arylethanol. The relative rates compared to $\alpha$-phenylethanol are as follows:

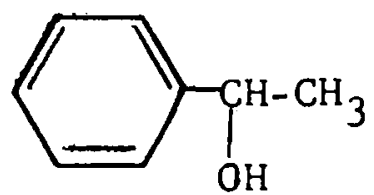

1.00

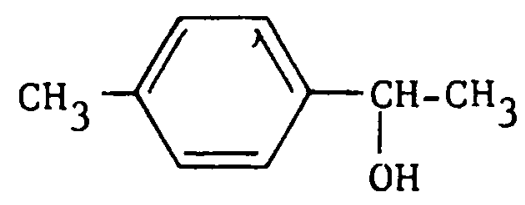

1.36

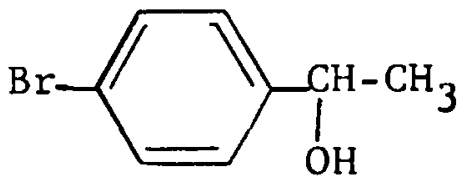

0.78

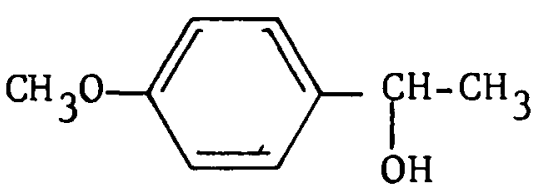

5.34 
TABLE II

OBSERVED INFRARED MAXIMA FOR THE CARBONYL (Frequency of Absorption Bands in $\mathrm{cm}^{-1}$ ) a

\begin{tabular}{l|r|c|c}
\hline & & $\alpha-$ Chloro- & Dichloroseleno- \\
\hline Acetophenone & 1688 & 1700,1680 & 1663 \\
p-Bromoacetophenone & 1685 & 1720,1698 & 1663 \\
p-Methoxyacetophenone & 1677 & 1714,1693 & 1655,1645 \\
p-Methylacetophenone. & 1670 & 1695,1675 & 1648 \\
Propiophenone & 1677 & 1695 & 1650 \\
Methyl t-buty1 ketone & 1712 & 1700 & \\
Acetone... & 1700 & 1710,1677 & \\
Methyl ethy1 ketone & 1700 & 1710 & \\
Cyclohexanone & 1700 & 1710,1677 & \\
\hline
\end{tabular}

${ }^{a} \mathrm{~A} 11$ of the spectra were obtained using a Perkin-E1mer Infracord double beam spectrophotometer with sodium chloride prisms. The spectra of a.11 the liquid and solid ketones were obtained using carbon tetrachloride as the solvent, while the solid dichloroselenoketores were determined in potassium bromide pe1lets. 
TABLE III

OBSERVED ULTRAVIOLET SPECTRAL DATA FOR THE CARBONYL $\left(\lambda_{\max } \text { is in } \AA\right)^{a}$

\begin{tabular}{l|c|c|c}
\hline & & $\alpha$-Chloro- & Dichloroséleno- \\
\hline & 2430 & 2470 & 2485 \\
Acetophenone & 2550 & 2580 & 2635 \\
p-Bromoacetophenone & 2740 & 2810 & 2850,2895 \\
p-Methoxyacetophenone & 2545 & 2575 & 2625 \\
p-Methylacetophenone & 2420 & 2450 & 2540 \\
\hline
\end{tabular}

${ }^{a}$ 11. of the spectra were determined in $95 \%$ ethy 1 alcohol using the Model 11 Cary recording ultraviolet spectrophotometer. 
Thus an electron donating group in the para position increases the rate of reaction while an electron withdrawing group decreases the reaction rate.

No dibromoselenoketone was ever isolated using selenium oxybromide. It has been reported by Kuncke11 and Zimmer-. mann 55 that the addition of bromine to selenoacetophenone, $\left(\mathrm{C}_{6} \mathrm{H}_{5} \mathrm{COCH}_{2}\right)_{2} \mathrm{Se}$, formed the white dibromoselenoacetophenone, m.p. $97^{\circ}$ 。 


\section{EXPERIMENTAL}

\section{Selenium Oxychloride Chlorinations}

\section{a. Selenium Oxychloride}

The selenium oxychloride was obtained from the J. T. Baker Chemical Company and was not further purified.

\section{b. Dichloroselenoacetophenone}

In a 500-m1., round-bottom flask was placed a cold solution of $48.2 \mathrm{gm}$. (0.4 mole) of acetophenone, b.p.197-199.0 (1it. 56 b.p. 202\%), $\mathrm{n}_{\mathrm{D}}^{28} 1.5302$ (1it. $57 \mathrm{n}_{\mathrm{D}}^{20.7} 1.5336$ ), dissolved in $200 \mathrm{ml}$. of ether which was protected by a calcium chloride drying tube. To this was added a solution of $33.2 \mathrm{gm} \cdot(0.2$ mole) of selenium oxychloride in $50 \mathrm{ml}$ of ether. The reaction mixture was occasionally swirled while being cooled in an ice-bath to moderate the exothermic reaction. During the course of the reaction the color of the solution changed from light yellow to deep yellow or to dark red depending upon the amount of solvent present.

After two hours the reaction mixture was filtered by suction to collect the desired precipitate which was washed with fresh solvent and dried. The white dichloroselenoacetophenone weighed $54.1 \mathrm{gm} .(70.3 \%), \mathrm{m}, \mathrm{p}, 120^{\circ}$ (1it. $\left.{ }^{58} \mathrm{~m} \circ \mathrm{p} .121,5^{\circ}\right)$.

${ }^{\mathrm{a}} \mathrm{A} 11$ melting and boiling points are uncorrected. 


\section{c. $\alpha$-Ch1oroacetophenone}

With a free flame, $25.0 \mathrm{gm}$. of solid dichloroselenoacetophenone was gently heated in air. During the initial melting process white fumes of hydrochloric acid: were evolved while the solution turned black. On further heating for an hour at $150-200^{\circ}$ the solution deposited some solid and more hydrochloric acid was evolved.

After cooling, the liquid residue was decanted from the black precipitate which was then washed with three 25-m1. portions of ether. There was recovered $4.85 \mathrm{gm} .(95.4 \%)$ of black selenium metal. The combined ether washes were added to the decanted residue, filtered, and dried with anhydrous magnesium sulfate. Evaporation of the ether followed by a vacuum distillation of the residue at $7 \mathrm{~mm}$. led to three fractions: "a? $0.90 \mathrm{gm}_{\text {。 }}$ of a colorless liquid, b.p. 70-80\%; "b" $1.90 \mathrm{gm}$. of a colorless liquid and a white solid, b.p. 80-100\%; and "cll 7.10 gm. of a white solid, b, p. 105-117\%. The products from the vacuum distillation were analyzed and characterized by the following techniques. A vapor phase chromatography (V.P.C.) analysis of "a" showed it to be pure acetophenone, $\mathrm{n}_{\mathrm{D}}^{28} 1.5322$ (1it. ${ }^{57} \mathrm{n}_{\mathrm{D}}^{20.7} 1.5336$ ) while ${ }^{10} \mathrm{~b}^{10}$ consisted of $65 \%$ acetophenone and $35 \% \alpha$-chloroacetophenone, $\mathrm{n}_{\mathrm{D}}^{28}$ 1.5394. The melting point of "c" was $56^{\circ}\left(1 \mathrm{it} .59\right.$ m.p. $\left.58^{\circ}\right)$. A positive Beilstein test 60 for halogen was obtained from " $\mathrm{c}^{n}$ and in the presence of a saturated solution of sodium iodide in acetone, 61 sodium chloride was deposited. The 2,4-dinitrophenylhydrazone of "cn melted at $218^{\circ}$ (1it. 65 m.p. 214-215\%). 
The infrared spectrum of ${ }^{\circ 0} a^{10}$ showed absorption maximum for the carbonyl at $1685 \mathrm{~cm}^{-1}$ (1it。 $621692 \mathrm{~cm}^{-1}$ ) while ${ }^{100} \mathrm{c}^{00}$ showed carbonyl peaks at 1700 and $1680 \mathrm{~cm}^{-1}$ (1it. 631704 and $\left.1682 \mathrm{~cm}^{-1}\right)$. There was recovered $7.75 \mathrm{gm}^{-1}(38.9 \%)$ of a-ch1oroacetophenone (1it. ${ }^{64}$ b.p. $140^{\circ}$ at $15 \mathrm{~mm}$ ) .

In an attempt to increase the yield of $\alpha$-chloroacetophenone the following techniques were tried. In a 250-ml.., round-bottom flask was placed a cold solution of $24.1 \mathrm{gm}$. $(0.2 \mathrm{~mole})$ of acetophenone dissolved in $100 \mathrm{ml}$. of $\mathrm{p}$-xylene which was protected by a calcium chloride drying tube. To this was added $16.6 \mathrm{gm} .(0.1$ mole) of selenium oxychloride in $25 \mathrm{ml}$. of p-xylene, The reaction mixture was swirled. occasionally in an ice bath and then allowed to stand for three hours during which crystalline dichloroselenoacetophenone formed.

The entire contents of the flask were reflused for 24 hours while the water which formed was removed from the mixture by means of a Dean-Stark apparatus. The liquid residue was decanted from the black precipitate which was then washed with three 25-m1. portions of ether. There was recovered $5.65 \mathrm{gm}_{\varphi}(71.5 \%)$ of selenium. The organic layers were combined and the solvents were evaporated.

The liquid residue was vacuum distilled at $2.5 \mathrm{~mm}$. and led to three fractions: " "a $2.54 \mathrm{gm}$. of a colorless liquid, b.p. 50-57\%;" "bv $5.14 \mathrm{gm}^{\circ}$ of a colorless liquid and a white solid, b.p. 57-920, and " ${ }^{\circ 00} 0.84 \mathrm{gm}$. of a white solid, b.p. 93-96०. The V.P.C. analysis of "a" showed it to be pure 
acetophenone, while ${ }^{.80} \mathrm{~b}^{00}$ consisted of $40 \%$ acetophenone and $60 \% \alpha$-chloroacetophenone. There was recovered $3.93 \mathrm{gm}$. (12.7\%) of $\alpha$-chloroacetophenone.

In another effort to increase the yield of $\alpha$-chloroacetophenone, $38.8 \mathrm{gm}$. ( $0.1 \mathrm{~mole})$ of dichloroselenoacetophenone was placed in a large test tube and slowly warmed in a mineral oil bath. At $50^{\circ}$ fumes of hydrochloric acid started to evolve; at $120^{\circ}$, the entire mixture liquified and more hydrochloric acid was evolved. The reaction mixture was kept for an hour at $175^{\circ}$.

The liquid residue was decanted from the black solid and washed with three $25-\mathrm{ml}$. portions of ether. There remained $7.6 \mathrm{gm} .(96.3 \%)$ of selenium. The combined ether washes were added to the decanted residue, filtered, and dried with anhydrous magnesium sulfate. Evaporation of the ether left $24.4 \mathrm{gm}$. (78\% of the theoretical $\alpha$-chloroacetophenone) of liquid. A vacuum distillation of the residue at $1 \mathrm{~mm}$. led to two fractions: " $300.7 \mathrm{gm}$. of a colorless 1iquid, acetophenone, $b$.p. $54-70^{\circ} ; " \mathrm{~b}^{01} 15.3 \mathrm{gm}$. (49.5\%) of a white solid, $\alpha$-chloroacetophenone, b.p. 71-92\%; and " ${ }^{\circ l}$ $5.4 \mathrm{gm}$ 。 of tar.

d. $\mathrm{D}$-Bromo- $\alpha$-chloroacetophenone

From $79.6 \mathrm{gm} .(0.4 \mathrm{~mole})$ of p-bromoacetophenone, m.p. $50^{\circ}\left(1\right.$ it. $\left.{ }^{66} \mathrm{~m} \cdot \mathrm{p}, 51^{\circ}\right)$ and $33.2 \mathrm{gm},(0.2 \mathrm{~mole})$ of selenium oxychloride, $46.8 \mathrm{gm}$. (42.9\%) of white dichloroseleno-p-bromoacetophenone, m.p. $125^{\circ}$, was obtained. 
The decomposition of $33.0 \mathrm{gm}$. of dichloroselenop-bromoacetophenone led to a recovery of $1.92 \mathrm{gm} .(40.2 \%)$ of black selenium. A vacuum distillation of the residue led to $10.9 \mathrm{gm} .(38.6 \%)$ of a yeliow-wite solid, p-bromo-

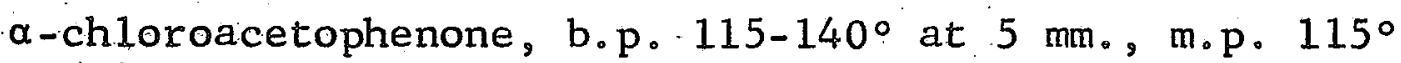
(1it. ${ }^{67} \mathrm{~m}, \mathrm{p}, 117-118^{\circ}$ ).

e. p-Methoxy-a-chloroacetophenone

From $30.0 \mathrm{gm} .(0.2 \mathrm{~mole})$ of $\mathrm{p}$-methoxyacetophenone, $\mathrm{m} \circ \mathrm{p} .38^{\circ}\left(1 \mathrm{it} .68 \mathrm{~m} \cdot \mathrm{p} .38-39^{\circ}\right)$, and $16.6 \mathrm{gm} \cdot(0.1 \mathrm{~mole})$ of selenium oxychloride, $38.2 \mathrm{gm}$. (86.5\%) of white dichloroseleno-p-methoxyacetophenone, m.p. $120^{\circ}\left(1 i t .69^{2} \mathrm{~m} \cdot \mathrm{p} \cdot 122^{\circ}\right)$ was obtained.

The decomposition of $32.0 \mathrm{gm}$ 。 of dichloroselenop-methoxyacetophenone led to a recovery of $5.5 \mathrm{gm} .(97.7 \%)$ of black metallic selenium. A vacuum distillation of the residue led to $10.7 \mathrm{gm} .(40.6 \%)$ of a white solid, p-methoxya-chioroacetophenone, b.p. $150-175^{\circ}$ at $8 \mathrm{~mm}$. (1it. 70 b.p. $179-181^{\circ}$ at $16-18 \mathrm{~mm}$ ) , m.p. $101^{\circ}$ (1it. ${ }^{1} \mathrm{~m} \cdot \mathrm{p} \cdot 102^{\circ}$ ).

f. p-Methy $1-\alpha$-chloroacetophenone

From $26.8 \mathrm{gm}$. (0.2 mole) of p-methylacetophenone, b.p. 218-221 $\left(1 i t .72\right.$ b.p. 2200), $\mathrm{n}_{\mathrm{D}}^{27} 1.5298$ (iit. ${ }^{73} \mathrm{n}_{\mathrm{D}}^{20}$ $1.5335)$, and $16.6 \mathrm{gm}$. ( 0.1 mole) of selenium oxychloride, $28.8 \mathrm{gm}$. (69.3\%) of white dichloroseleno-p-methylacetophenone, m.p. $128^{\circ}\left(1 i t .58 \mathrm{~m} \cdot \mathrm{p} .129^{\circ}\right)$; was obtained. 
The decomposition of $18.0 \mathrm{gm}$. of dichloroseleno-pmethylacetophenone led to a recovery of $3.2 \mathrm{gm} .(93.6 \%)$ of black metallic selenium. A vacuum distillation of the residue led to two fractions: "an $2.9 \mathrm{gm}$. of a colorless 1iquid, p-methylacetophenone, b.p.95-1350 at $8 \mathrm{~mm}, \cdot \mathrm{n}_{\mathrm{D}}^{27}$ 1.5347 (1it. ${ }^{73}$ b.p.o $93.5^{\circ}$ at $7 \mathrm{~mm} \cdot, \mathrm{n}_{\mathrm{D}}^{20}$ 1.5335); and "bov $5.6 \mathrm{gm} .(38.7 \%)$ of a white solid, p-methyl-a-chloroaceto-

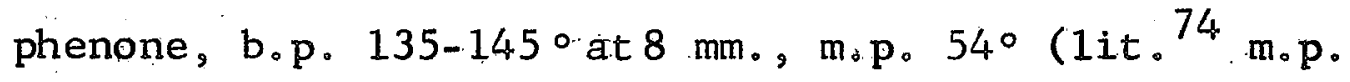
$\left.55-56^{\circ}\right)$ 。

g. a-Chloropropiophenone

From $26.8 \mathrm{gm} .(0.2 \mathrm{~mole})$ of propiephenone, $\mathrm{b}_{\circ} \mathrm{p}$ 。 $213-216^{\circ}$ (1it. ${ }^{75}$ b.p. 2170), $\mathrm{n}_{\mathrm{D}}^{32} 1.5211$ (1it. ${ }^{76} \mathrm{n}_{\mathrm{D}}^{20} 1.5270$ ), and $16.6 \mathrm{gm}$. (0.1 mole) of selenium oxychloride, $19.3 \mathrm{gm}$. (46.4\%) of white dichloroselenopropiophenone, m.p. $122^{\circ}$ (1it. $77^{\circ} \mathrm{m}, 124^{\circ}$ ), was obtained.

The decomposition of $11.0 \mathrm{gm}$. of dichloroselenopropiophenone led to a recovery of $1.7 \mathrm{gm} .(71.8 \%)$ of black metallic selenium. A vacuum distillation of the residue led to $3.7 \mathrm{gm} .(41.6 \%)$ of a yellow liquid, $\alpha$-chloropropiophenone, $b \cdot p \cdot 104-116^{\circ}$ at 9 mm。, $n_{D}^{28} 1.5340$ (1it.78 b.p. $123-125^{\circ}$ at $\left.17 \mathrm{~mm}, \mathrm{n}_{\mathrm{D}}^{25} 1.5402\right)$.

h. 3,3-Dimethy1-1-chloro-2-butanone

From $20.0 \mathrm{gm} .(0.2$ mole) of methyl t-butyl ketone, b.p. $101-103^{\circ}$ (1it. 79 b.p. 105 $), n_{D}^{31} 1.3909$ (1it. ${ }^{80} n_{D}^{25}$ 
$1.3944)$, and $16.6 \mathrm{gm}$. (0.1 mole) of selenium oxychloride, $24.1 \mathrm{gm} \cdot(69.4 \%)$ of white dich loroseleno-methy $1 . t$-buty 1 ketone, m.p. $122^{\circ}$; was obtained. The decomposition of $24.1 \mathrm{gm}_{\text {. }}$ of dichloroselenomethyl t-butyl ketone led to a recovery of $3.8 \mathrm{gm}$. $(69.6 \%)$ of black selenium. A vacuum distillation of the residue led to $8.5 \mathrm{gm},(45.7 \%)$ of a yellow liquid, 3,3-dimethy 1-1chlore-2-butanone, b.p. $47-51^{\circ}$ at $2 \mathrm{~mm} \cdot \mathrm{n}_{\mathrm{D}}^{31} 1.4358$ (1it. ${ }^{81}$ b.p. $75-76^{\circ}$ at $\left.15 \mathrm{~mm}, \mathrm{n}_{\mathrm{D}}^{20} 1.4422\right)$.

\section{i. Chloroacetone}

From $11.6 \mathrm{gm} .(0.2 \mathrm{~mole})$ of acetone, b.p. $54^{\circ}$ (1it. $^{82}$ b.p. $\left.56.2-56.3^{\circ}\right), n_{D}^{27} 1.3558\left(1 i t{ }^{83} n_{D}^{25} 1.35695\right)$, and 16.6 gm. $\left(0.1\right.$ mole) of selenium oxychloride, $21.8 \mathrm{gm}_{0}(82.7 \%)$ of a white solid dichloroselenoacetone, m.p. $84^{\circ}\left(1\right.$ lit $^{84} \mathrm{~m} \cdot \mathrm{p}$. 82.), was obtained.

The decomposition of $20.0 \mathrm{gm}$. of dichloroselenoacetone led to a recovery of $4.3 \mathrm{gm} .(71.8 \%)$ of black selenium, Distillation of the residue led to $5.45 \mathrm{gm}$. $(37.1 \%)$ of chloroacetone, a colorless 1iquid, b.p. $114-120^{\circ}$ (1it.85 b.p. 1190), $\mathrm{n}_{\mathrm{D}}^{26} 1.4317$ (1it. $\left.{ }^{86} \mathrm{n}_{\mathrm{D}}^{1.9 .5} 1.4340\right)$.

\section{j. 3-Chloro-2-butanone}

In a 250-m1. round-bottom flask was placed a solution of $14.4 \mathrm{gm}$. ( $0.2 \mathrm{~mole})$ of methyl ethyl ketone, b.p.76-770, $\mathrm{n}_{\mathrm{D}}^{27} 1.3758\left(1 \mathrm{it} .{ }^{87} \mathrm{~b} \cdot \mathrm{p} \cdot 79.5^{\circ}, \mathrm{n}_{\mathrm{D}}^{25} 1.3761\right)$, in $100 \mathrm{ml}$. of 
ether cooled in a Dry Ice-acetone slush which was protected by a calcium chloride drying tube. To this was added a solution of $16.6 \mathrm{gm}$. $(0.1 \mathrm{~mole})$ of selenium oxychloride in $25 \mathrm{ml}$. of ether. After a couple of hours the colorless solution turned from yellow to red while being swirled occasionally in an ice bath. It was found best to allow this mixture to stand for a few days so that all the red amorphous sëlenium could deposit itself:

The liquid residue was decanted from the red solid which was then washed with three $25-\mathrm{ml}$ 。 portions of ether。 There remained $6.95 \mathrm{gm},(88.2 \%)$ of red selenium. The combined ether washes were added to the decanted residue, filtered, and dried with anhydrous magnesium sulfate. Evaporation of the ether followed by a distillation of the residue led to 7.35 gm. $(34.5 \%)$ of a yellow 1iquid, 3-ch1oro-2-butanone, $b \circ p$. $110-1170\left(10^{\circ}{ }^{88}\right.$ b.p. $\left.114-115^{\circ}\right), n_{D}^{27} 1.4185\left(1 i t .{ }^{89} n_{D}^{20}\right.$ 1.417i)。

k. 2-Ch1orocyclohexanone

In a 250-m1. round-bottom flask was placed a cold solution of $19.6 \mathrm{gm}$. (0.2 mole) of cyclohexanone, b.p. $151-152^{\circ}$ (1it. ${ }^{90}$ bop. 155.6.155.70), $\mathrm{n}_{\mathrm{D}}^{25} 1.4481$ (1it. ${ }^{91} \mathrm{n}_{\mathrm{D}}^{16} 1.4521$ ), in $100 \mathrm{ml}$. of ether which was protected by a calcium chloride drying tube. To this was added a solution of $16.6 \mathrm{gm}$. $(0.1$ mole) of selenium oxychloride in $25 \mathrm{~m} 1$. of ether over a period 
of two minutes. The reaction mixture was frequentiy swirled in an ice bath to moderate the exothermic reaction. During the course of the reaction the color of the solution changed from light yellow to deep red.

The ether was evaporated and the residue gently heated in air with a free flame for an houx. The liquid residue was decanted from the red amorphous selenium and then washed with three $25-\mathrm{ml}$, portions of ether. The combined ether washes were added to the decanted residue, filtered, and dried with anhydrous magnesium sulfate. Evaporation of the ether followed by a vacuum distillation of the residue at 3 $\mathrm{mm}$. led to three fractions: "a" $1: 13 \mathrm{gm}$. of a colorless liquid, b.p. $38-50^{\circ}, n_{D}^{29} 1.4537 ; 00 b^{00} 0.524 \mathrm{gm}$ of a colorless 1iquid, b.p. $57-70^{\circ}, \mathrm{n}_{\mathrm{D}}^{29} 1.4751$; and ${ }^{00} \mathrm{c} 00 \mathrm{c} 76 \mathrm{gm}^{0}$ of a color-

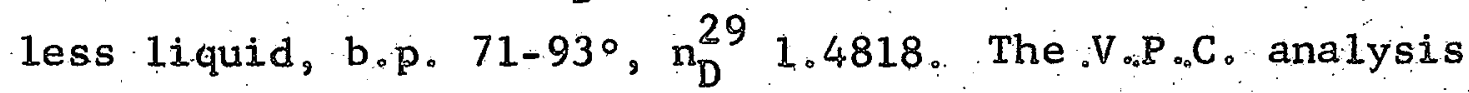
showed "an pure cyclohexanone (1it, 91 bo p. 470 at $15 \mathrm{~mm}$, $\mathrm{n}_{\mathrm{D}}^{16.9} 1.4521$ ), "b" consisted of $60 \%$ cyclohexanone and $40 \%$ 2-chlorocyclohexanone, and " $\mathrm{c}$ " was pure 2-chlorocyclohexanone (iit. 92 b.p. $78-78.5^{\circ}$ at $7 \mathrm{~mm}, \mathrm{n}_{\mathrm{D}}^{20}$ 1.4831). There was recovo ered $10.85 \mathrm{gm} .(40.8 \%)$ of 2 -chlorocyclohexanone.

In a 500-ml。 round-bottom flask was placed a solution of $19.6 \mathrm{gm} .(0.2 \mathrm{~mole})$ of cyclohexanone dissolved in $150 \mathrm{ml}$. of ether which was protected by a calcium chloride drying tube. To this was added a solution of $16.6 \mathrm{gm}$. $(0.1 \mathrm{~mole})$ of selenium oxychloride in $25 \mathrm{ml}$. of ether while the flask 
was cooled in a Dry Ice-acetone slush bath. After a few minutes of swirling in an ice bath a whitish-yellow solid precipitated out of solution. Most of the solid was a homogeneous mass that could not be broken up; however; a few white crystals of dich loroselenocyclohexanone were isolated, m.p. 46\%. After an hour at room temperature red selenium started to deposit out of the homogeneous mass. The reaction mixture was allowed to remain undisturbed for a few days so that all the selenium could deposit itself out of solution.

The liquid residue was decanted off from the red solid which was then washed with three $25-\mathrm{ml}$. portions of ether. There was recovered $7.2 \mathrm{gm} \cdot(91.3 \%)$ of red amorphous seleniuin. The combined ether washes were added to the decanted residue, filtered, and dried with anhydrous magnesium sulfate. Evaporation of the ether followed by a vacuum distillation of the residue at $2 \mathrm{~mm}$. led to two fractions: "9 a 1.6. gm。 of a colorless liquid; b.p.40-50\%, $\mathrm{n}_{\mathrm{D}}^{26} 1.4602$; and ${ }^{00} 9.8 \mathrm{gm}_{\circ}$ of a colorless 1iquid, $b_{\circ} \mathrm{p}_{0} .50-56^{\circ}, \mathrm{n}_{\mathrm{D}}^{26}$ 1.4787. The V...P. C. analysis showed "la" consisted of $60 \%$ cyclohexanone and $40 \% 2$-chlorocyclohexanone while ${ }^{00}$ was pure 2-chlorocyclohexanone. There recovered $10.34 \mathrm{gm}$. (39. $1 \%$ ) of 2 -chlorocyclohexanone. 
TABLE IV

BRE \&ARATIONAL DATA AND MELTING POINTS

\begin{tabular}{l|l|c|c|c|}
\hline \multicolumn{1}{c|}{ Retone } & $\begin{array}{c}\text { Dichloroseleno- } \\
\text { Formula }\end{array}$ & $\begin{array}{c}\text { Melting } \\
\text { Point }\end{array}$ \\
\hline Acetophenone & $\begin{array}{l}\left(\mathrm{C}_{6} \mathrm{H}_{5} \mathrm{COCH}_{2}\right)_{2} \mathrm{SeCl}_{2} \\
\left(\mathrm{BrC}_{6} \mathrm{H}_{4} \mathrm{COCH}_{2}\right)_{2} \mathrm{SeCl}_{2}\end{array}$ & $120^{\circ}$ \\
p-Bethoxyacetophenone & $\begin{array}{l}\left(\mathrm{CH}_{3} \mathrm{OC}_{6} \mathrm{H}_{4} \mathrm{COCH}_{2}\right)_{2} \mathrm{SeCl}_{2} \\
\text { p-Methylacetophenone } \\
\text { Propiophenone }\end{array}$ & $120^{\circ}$ \\
Methyl t-buty1 ketone & $\left(\mathrm{CH}_{3} \mathrm{C}_{6} \mathrm{H}_{4} \mathrm{COCH}_{2}\right)_{2} \mathrm{SeCl}_{2}$ & $128^{\circ}$ \\
Acetone & $\left(\mathrm{C}_{6} \mathrm{H}_{5} \mathrm{COC}_{2} \mathrm{H}_{4}\right)_{2} \mathrm{SeCl}_{2}$ & $124^{\circ}$ \\
Cyclohexanome & $\left(\mathrm{C}_{4} \mathrm{H}_{9} \mathrm{COCH}_{2}\right)_{2} \mathrm{SeCl}_{2}$ & $122^{\circ}$ \\
$\left(\mathrm{CH}_{3} \mathrm{COCH}_{2}\right)_{2} \mathrm{SeCl}_{2}$ & $84^{\circ}$ \\
$\left(\mathrm{C}_{4} \mathrm{H}_{8} \mathrm{COCH}_{2} \mathrm{SeCl}_{2}\right.$ & $46^{\circ}$ \\
\hline
\end{tabular}




\section{Selenium Oxybromide Brominations}

\section{a. Selenium Oxybromide}

To prepare selenium oxybromide, ${ }^{32}$ commercial selenium dioxide was purified by adding a few drops of fuming nitric acid and gently heating with a free flame until the selenium dioxide sublimed into long white needles. There was ground together in a mortar $5.50 \mathrm{gm}$. (0.05 mole) of selenium dioxide with $3.98 \mathrm{gm} .(0.05 \mathrm{~mole})$ of black powdered selenium and the solid mixture was then placed in a 200-ml. round-bottom flask to which was attached a dropping funnel containing $15.98 \mathrm{gm}$. ( 0.1 mole $)$ of bromine. The flask was surrounded by an ice bath in order to moderate the exothermic reaction. After all the bromine had been added, the mixture of selenium tetrabromide and selenium dioxide was warmed for an hour on a water bath at $40-50^{\circ}$ forming selenium oxybromide as a liquid orange-brown mass.

\section{b. a-Bromoacetophenone}

To the cooled seleni.um oxybromide was added 24.1 . $\mathrm{gm}$. (0.2 mole) of acetophenone in $25 \mathrm{ml}$. of ether. The heterogeneous mixture was warmed on a water bath at $30-35^{\circ}$ until a homogeneous solution formed. The reaction mixture was briefly cooled in an ice bath and after a few minutes fine white grain crystals formed which were identified as selenium dioxide... Five hours later solid black selenium 
began to precipitate out of solution. The reaction mixture was left undisturbed overnight.

The following day: the liquid residue was decanted and two $25 \mathrm{ml}$. portions of ether were used to wash the black and white solid. The combined ether washes were added to the black liquid residue; the solution was filtered three times resulting in a pale yellow solution. There was recovered $24 \% 95 \mathrm{gm}$. $(62.7 \%)$ of $\alpha$-bromoacetophenone by a water vacuum distillation of the ether.

The product, a-bromoacetophenone, was identified by employing the following techniques. The white solid melted at $52^{\circ}\left(1 \mathrm{it}^{93} \mathrm{~m} \cdot \mathrm{p}, 50^{\circ}\right)$. A mixed melting point with an authentic sample did not depress the melting point. A positive Beilstein test ${ }^{60}$ for halogen was obtained and in the presence of a saturated solution of sodium iodide in acetone 61 sodium bromide was deposited. The infrared spectrum showed absorption maximum for the carbonyl at 1690 and $1675 \mathrm{~cm}^{-1}$.

c. 3,3-Dimethy 1-1-bromo-2-butanone

To the solid selenium oxybromide was added $200 \mathrm{gm}$. $(0.2 \mathrm{~mole})$ of pinacolone. The same procedure was followed as with acetophenone except that upon the evaporation of the ether a liquid residue remained. A vacuum distillation of the residue led to $16.45 \mathrm{gm} .(46.1 \%)$ of 3,3 -dimethy $1-1$ bromo-2-butanone, a yellow liquid, b.p. 45-510 at $1.5 \mathrm{~mm}$, $\mathrm{n}_{\mathrm{D}}^{23}$ 1.4693 (1it. ${ }^{94}$ b.p. 590 at $4 \mathrm{~mm}, \mathrm{n}_{\mathrm{D}}^{25} 1.4659$ ). 


\section{d. 2-Bromocyclohexanone}

To the solid selenium oxybromide was added $19.6 \mathrm{gm}$ 。 (0.2 mole) of cyclohexanone. The same procedure was followed as with pinacolone. A vacuum distillation of the liquid residue at $7 \mathrm{~mm}$. led to three fractions: $10 a^{\text {no }} 1.19$ $\mathrm{gm}_{0}$ of a clear liquid, b.p. $30-50^{\circ}, \mathrm{n}_{\mathrm{D}}^{24} 1.4844^{\circ}$, bo $3.46 \mathrm{gm}_{0}$ of a pale yellow 1iquid, b.p. $50-650, n_{D}^{24} 1.5022 ; 00 c^{00} 7.55$ $\mathrm{gm}_{\circ}$ of a ye11ow 1iquid, b.p.65-78, $\mathrm{n}_{\mathrm{D}}^{24} 1.5115$. The V.P.C. analysis of ${ }^{00} a^{90}$ showed $80 \%$ cyclohexanone (1it ${ }^{91}$ b.p. 470 at $15 \mathrm{~mm}_{0}, \mathrm{n}_{\mathrm{D}}^{16.9} 1.4521$ ) and $20 \%$-bromocyclohexanone, $00 \mathrm{~b}$ consisted of $10 \%$ cyclohexanone and $90 \%$-bromocyclohexanone, and ${ }^{10} \mathrm{C}^{00}$ consisted of pure 2-bromocyclohexanone (1it. ${ }^{95}$ b.p. 112-1130 at $\left.20 \mathrm{~mm}_{0} \mathrm{n}_{\mathrm{D}}^{25} 1.5085\right)$. There was recovered $10.9 \mathrm{gm}$. $(30.8 \%)$ of 2-bromocyclohexanone.

\section{Selenium Tetrachloride Chlorination}

a. Selenium Tetrachloride

In a $45-\mathrm{cm}$. long Pyrex tube having an inside diameter of $25 \mathrm{~mm}$. was placed $15.9 \mathrm{gm}$. $(0.2 \mathrm{~mole})$ of black powdered selenium. Chlorine was generated by dripping concentrated hydrochloric acid on potassium permanganate and allowing the vapors to first pass through concentrated sulfuric acid. Diselenium dichloride formed almost immediately with the evolution of heat. Gentle heating with a microburner for about one hour led to $35.6 \mathrm{gm}$. $(79.6 \%)$ of yellow crystalline selenium tetrach loride. 
b. Dichloroselenoacetophenone

In a $500-\mathrm{ml}$ 。 round-bottom flask was placed a cold solution of $36.1 \mathrm{gm}$. $(0.3 \mathrm{~mole})$ of acetophenone dissolved in $800 \mathrm{ml}$ of ether. To this was added $33.1 \mathrm{gm}$ 。 ( $0.15 \mathrm{~mole})$ of selenium tetrachloride and the mixture magnetically stirred for two hours. After filtering and drying $35.8 \mathrm{gm}$ 。( $(61.6 \%)$ of white dichloroselenoacetophenone, $m_{\circ} p .120^{\circ}$, was recovered。

\section{c. a-Chloroacetophenone}

In a large test tube $32.0 \mathrm{gm}$. $(0.0825 \mathrm{~mole})$ of dichloro: selenoacetophenone was heated in mineral oil bath for one hour at $175^{\circ}$ during which fumes of hydrochloric acid were given off. The liquid residue was decanted with ether leaving behind 6.3 gm。 $(96.8 \%)$ of selenium. Evaporation of the ether left 20.1 $\mathrm{gm} .(79.8 \%$ of the theoretical $\alpha$-chloroacetophenone) of liquid. A vacuum distillation of the residue at $1.5 \mathrm{~mm}$. led to two Fractions: $00 a^{10} 0.9 \mathrm{gm}$ of a color less liquid, acetophenone, b.p. $59-73^{\circ} ; 00 \mathrm{~b}^{00} 12.5 \mathrm{gm}$. $(49.1 \%)$ of a white solid, $\alpha$-chloroacetophenone, $b . p .74-92^{\circ}$; and $:{ }^{0} \mathrm{c}^{\mathrm{N}} 6.7 \mathrm{gm}$. of tar.

\section{Sodium Borohydride Reductions}

a. Q-Phenylethanol (from acetophenone)

In a 250-m1. round-bottom flask was added $12.0 \mathrm{gm}$. (0.1 mole) of acetophenone dissolved in $100 \mathrm{~m} 1$. of absolute ethanol; to this was added $1.25 \mathrm{gm}$. $(0,033$ mole $)$ of sodium 
borohydride, a slight excess. The reaction mixture was heated on a water bath at $90-100^{\circ}$ until most of the ethanol had evaporated. The remaining liquid was extracted with $100 \mathrm{ml}$ of ether which was added to a separatory funnel containing $100 \mathrm{ml}$ of water. The upper ether layer was extracted, filtered, and dried with anhydrous magnesium sulfate. After evaporation of the ether a distillation of the residue led to $10.3 \mathrm{gm},(85.8 \%)$ of a colorless liquid, a-phenylethano1, b.p. 195-1980 (1it. 96 b.p. 202-2040), $\mathrm{n}_{\mathrm{D}}^{22} 1.5262(1 \mathrm{it} .971 .5244)$. The $\mathrm{N}$-phenylcarbamate derivative melted at $91^{\circ}\left(1\right.$ it. $\left.98^{\circ} \mathrm{m} . \mathrm{p} .92^{\circ}\right)$.

b. Q-Phenylethanol (from dichloroselenoacetophenone)

In a 500-m1. round-bottom flask was added $7.75 \mathrm{gm}$. $(0.02 \mathrm{~mole})$ of dichloroselenoacetophenone in $200 \mathrm{ml}$ of absolute alcohol. The reaction mixture was refluxed until all the solid dissolved; as excess sodium borohydride, 2.0 gm, was added, the solution turned red as selenium began to deposit out and colorless as selenium was further reduced. The reaction mixture was heated on a water bath at $90-100^{\circ}$ until most of the alcohol evaporated. The remaining liquid was extracted with $100 \mathrm{ml}$ of ether which was added to a separatory funnel containing $100 \mathrm{ml}$ of water. The upper ether layex was extracted and dried with anhydrous magnesium sulfate. After evaporation of the ether a vacuum distiliation 
of the residue led to $3.56 \mathrm{gm},(80.8 \%)$ of a colorless liquid, a-phenylethanol, b.p. $84-97^{\circ}$ at $8 \mathrm{~mm}$. (1it. ${ }^{99}$ b.p. $85-86^{\circ}$ at $\left.7 \mathrm{~mm}_{\circ}\right), \mathrm{n}_{\mathrm{D}}^{25} 1.5242\left(1 \mathrm{it} .{ }^{97} \mathrm{n}_{\mathrm{D}}^{25} 1.5244\right)$.

\section{c. p-Bromophenyl- $\alpha$-ethanol}

From $19.9 \mathrm{gm}^{\circ}(0.1 \mathrm{~mole})$ of $\mathrm{p}$-bromoacetophenone and $1.25 \mathrm{gm}_{0} \cdot(0.033$ mole $)$ of sodium borohydride, $15.9 \mathrm{gm}$. $(79.8 \%)$ of a colorless liquid, p-bromophenyl-a-ethanol, b.p.125-128 at $8 \mathrm{~mm}$, (1it. 100 bop. 133-1340 at $15 \mathrm{~mm}_{\circ}$ ), $\mathrm{n}_{\mathrm{D}}^{28} 1.5651$ (1it. 101 $n_{D}^{18} 1.5740$ ), was obtained after a vacuum distillation of the residue.

\section{d. p-Methoxypheny 1- $\alpha$-ethano1}

From $15.0 \mathrm{gm} .(0.1 \mathrm{~mole})$ of $\mathrm{p}$-methosyacetophenone and $1.25 \mathrm{gm}_{0} .(0.033 \mathrm{~mole})$ of sodium borohydride, $11.7 \mathrm{gm} .(77.9 \%)$ of a colorless liquid, p-methoxyphenyl- $\alpha$-ethanol, $b$ op. 122-1250 at $8 \mathrm{~mm}$ (1ito ${ }^{102}$ b.p. $110^{\circ}$ at $13 \mathrm{~mm}$ ), $n_{D}^{26} 1.5313$, was obtained after a vacuum distillation of the residue.

e. D-Methy1 Dheny 1- $\alpha$-ethano1

From $13.4 \mathrm{gm} .(0.1 \mathrm{~mole})$ of $\mathrm{p}$-methylacetophenone and $1.25 \mathrm{gm}_{\circ}(0.033 \mathrm{~mole})$ of sodium borohydride, $11.2 \mathrm{gm}(83.6 \%)$ of a colorless liquid, p-methylpheny1- $\alpha$-ethano $1, b . p .95-990$ at $8 \mathrm{~mm}$. (1it. ${ }^{103}$ bop. $109-110^{\circ}$ at $19 \mathrm{~mm}$ ), $\mathrm{n}_{\mathrm{D}}^{28} 1.5179$, was obtained after a vacuum distillation of the residue. 


\section{f. Rate Study}

In a 200-m1. round-bottom flask was placed $14.1 \mathrm{gm}$ 。 (0.117 mole) of acetophenone and $15.7 \mathrm{gm}$. (0.117 mole) of p-methylacetophenone dissolved in $100 \mathrm{ml}$. of ether, which was protected by a calcium chloride drying tube. To this was added $0.975 \mathrm{gm}$. (0.00586 mole) of selenium oxychloride. The reaction mixture was occasional1y swirled and allowed to stand at room temperature for two hours. The desired precipitate was filtered, washed with fresh solvent, and dried. There was recovered $1.6 \mathrm{gm}$. of a white selenium adduct. This was reduced with excess sodium borohydride to $\alpha$-pheny 1 ethano 1 and p-methylpheny1-o-ethano1. The V.P.C. analysis showed that the ratio of the alcohols was 1.00 to 1.36 respectively.. This was run on an Aerograph instrument equipped with a silicone column.

Using the same technique, from $14.1 \mathrm{gm}$ ( $(0.117$ mole) of acetophenone, $17.6 \mathrm{gm}_{\circ} \cdot(0.117$ mole $)$ of p-methoxyacetophenone, and $0,975 \mathrm{gm}$. (0.00586 mole) of selenium oxychloride, $1.5 \mathrm{gm}$. of a white selenium adduct was obtained. Reduction with sodium borohydride led to $\alpha$-phenylethanol and p-methoxypheny $1-\alpha$-ethanol in the ratio of 1.00 to 5.34 respectively. Similarly from $10.8 \mathrm{gm} .(0.0898$ mole) of acetophenone, 17.6. gm: $\left(0.0898\right.$ mole) of p-bromoacetophenone, and $0.731 \mathrm{gm}_{\text {。 }}$ (0.0045 mole) of selenium oxychloride; $1.1 \mathrm{gm}$ of a white selenium adduct was obtained Reduction with sodium. 
borohydride led to $\alpha$-phenylethano 1 and p-bromopheny $1-\alpha-$ ethanol in the ratio of 1.00 to 0.78 respectively.

\section{Miscellaneous}

\section{a. Acetophenone}

In a 500-ml. round-bottom flask was added $11.6 \mathrm{gm}$. $(0.03 \mathrm{~mole})$ of dichloroselenoacetophenone in $300 \mathrm{~m} 1$. of absolute alcohol. The reaction mixture was refluxed until all the solid dissolved and then $3.90 \mathrm{gm} .(0.06$ mole $)$ of powdered zinc, a $100 \%$ excess was added. Almost immediately red selenium formed and the reaction mixture was heated on a water bath at $90-100^{\circ}$ for about an hour until most of the alçohol evaporated. The remaining liquid was extracted with $100 \mathrm{ml}$. of ether which was added to a separatory funnel containing $100 \mathrm{~m} 1$ of water. The upper ether layer was extracted and dried with anhydrous magnesium sulfate. After evaporation of the ether a distillation of the residue led to $2.2 \mathrm{gm}$. $(30.9 \%)$ of a colorless 1iquid, acetophenone, b.p. $81-86^{\circ}$ at $8 \mathrm{~mm}$. (1it. 73 b.p. $88.5^{\circ}$ corrected at $16 \mathrm{~mm}$ ), $\mathrm{n}_{\mathrm{D}}^{28} \mathrm{1}_{0.5281}$ (1it. $57 \mathrm{n}_{\mathrm{D}}^{20.7} 1_{.5336) \text {. }}$ 


\section{BIBLIOGRAPHY}

1. R. Weber, Pogg. Ann, , 108, 615 (1859).

2. A. Michae1is, Ann., 240, 150 (1887).

3. C. A. Cameron and J. Macallan, Chem, Rev., 59, 267 (1887)。

4. V. Lenher, J. Am. Chem. Soc., 42, 2498 (1920).

5. G. B. L. Smith and J. Jackson, in L. F. Audrieth (ed.), "Inorganic Synthesis," McGraw-Hi11 Co., New York, Vo1. III, pp. $130-137$ (1950).

6. V. Lenher, J.Am。.Chem. Soc. 43, 29 (1921).

7. V. Lenher, J. Am. Chem. Soc. , 44, 1664 (1922)。

8. V: Lenher, J. Phys. Chem., 26, 156 (1922)。

9. C. W. Muehlberger and V. Lenher, J. Am. Chem. Soc., 47, 1843. (1925)。

10. H. C. Dudley, U. S. Public Health Reports, 53, 94 (1938).

11. A. Michaelis and B..Landmann, Ann., 241, 156 (1887).

12. W. Strecker and W. Danie1, Ann., 462, 186 (1928).

13. E. Godehaux, Ber。, 24, 765 (1891).

14. B. Edgington and J. B. Frith, J. Soc. Chem. Ind. Trans., $\underline{\underline{5}} \underline{\underline{5}}, 192$ (1936)。

15.. J. Jackson and G. B. L. Smith, J. Am. Chem. Soc., 62, 545 :(1940).

16. R. E. Nelson, R. A. Schroeder and W. R。 Bunting, J.Am。 Chem..Soc., 55, 801 (1933)。

17. F。N.Alquist and R.E.Nelson, J.Am. Chem. Soc., 53, 4033 (1931)。

18. A. Michaelis and $F_{0}$, Kunckel1, Ber, 30, 2823 (1897)。 
19. No. Strecker and A. Willing, Ber. 48, 196 (1915)。

20.. A. Mueller, Chem。-Ztg。, 433, 843 (1919).

21. R. E. Ne1son and R: J. Jones, J.Am。Chem。Soc., 52, 1588 (1930).

22. J. P. Schaefer and F. M. Sonnenberg, J. Org. Chem., 28, 1128 (1963)。

23. C. E. Frick, J. Am。 Chem。.Soc., 45, 1795 (1923).

24. Vo. Lenher, J. Am. Chem. Soc., 43, 33 (1921).

25. H. Brintzinger, $K_{0}$. Pfannstill and H. Voge1, Z. Anorg. Chem., 256, 80 (1948)。

26. F. Kuncke11, Ber。, 28, 609 (1895)。

27. G. T. Morgan and F. H. Burnsta,11, J. Chem. Soc., 3260 . (1928).

28. A. Michaelis, Ber., 30, 2821 (1897).

29. Kuncke11 and R. Zimmermann, Ann, 314, 281 (1901).

30. A. Schneider, Pogg. Ann, 129, 459 (1866)。

31. R. Glauser, Z. Anorg. Chem。, 80, 277 (1913).

32. V. Lenher, J. Am。Chem.Soc, 44, 1668 (1922).

33. J.K

34. J. J. Berzelius, Svenska Akad Hand1., 18 (1818).

35. A. Michaelis, Jenaische Z. Med. Naturw。, 6, 87 (1871)。

36. A. Michaelis, Jenaische Z. Med. Naturwo, 6; 95 (1871)。

37. Fo. Clausnizer, Ann。, 196, 283 (1879).

38. F。:Clausnizer, Ann, 196, 284 (1879).

39. $V_{0}$. Lenher and $H_{0}$ B. North, J.Am。 Chem。 Soc, 29, 33 (1907)。

40. J.H. Simons, J. Am. Chem。Soc。, 52, 3486 (1930). 
41. D. Mo Yost and C. E. Kircher, J. Am. Chem。 Soc.' 52 ; 4685 (1930).

42. F. Clausnizer, Ann., 196, 290 (1897).

43. E. Beckmann and R. Hansiian, Z. Phys. Chem., 70, 8 (1910).

44. O. Hinsberg, Ann., 260, 42 (1890).

45. W. Cornelius, J. Pr. Chem. (2), 88, 395 (1913).

46. W. Strecker and A. Willing, Ber. 48, 197 (1915)。

47. G. T. Morgan, H. D. K. Drew, J. Chem。Soc., 117, 1456 (1920).

48. G. T. Morgan and H. G. Reeyes, J. Chem. Soc。, 123, 444 (1923).

49. G. T. Morgan, J. Chem. Soc., 554 (1935)。

50. Co Chabrié, Bul1. Soc. Chim. France, (2), 50, 133 (1888).

51. C. Chabriè, Bul1. Soc。Chim. France, (3), ㄹ, 789 (1889)。

52. C. Chabriè, Compt Rend., 109, 182 (1889).

53. C. Chabrié, Ann. Chim. Phys. (6), 20, 214 (1890).

54. H. C. Bel1 and C. S. Gibson, J. Chem. Soc。, 127, 1877 (1925)。

55. F. Kuncke11 and R. Zimmermann, Ann, 314, 284 (1901).

56. F. U. Grimm and W. A. Patrick, J.Am. Chem. Soc. 45, 2799 (1923).

57. F。 Krol1pfeiffer, Ann. 430, 202 (1922).

58. $R_{0}$ E. Ne1son and $R . N$. Jones, J.Am。Chem. Soc., 52, 1589 (1930).

59. So Goldschmidt, :R. Endres, and R. Dirsch, Ber。, 58, 576 (1925).

60. S. M。 McE1vain, . "Characterization of Organic Compounds, Mạcmillan Co., New York, p.42 (1958)。 
61. R. L. Shriner, R。.C. Fuson and D。Y.Curtin, pystematic Identification of Organic Compounds," J. Wi.ley and Sons, Inc., New York, p. 144 (1960)。

62. L. J。 Bellamy, Lo Co Thomas and Ro L. Williams, Jo Chem。 Soc., $3706 \cdot(1956)$.

63. L。 J. Bellamy and R. L. Williams, J.Chem. Soc., 4297 (1957)。

64. A, Dotoeuf, Bu11. Soc, Chim. France, (4), 31, 177, (1922).

65. N. Campbe11 and E. B. McCa11, J。.Chem. Soc ., 2873 (1950).

66. R. Schweitzer, Ber, 24, 550 (1891).

67. H. H. Pokras and H. I. Bernstein, J. Am. Chem. Soc., 65, 2096 (1943)。

68. L. Gattermann, R. Ehrhardt and H. Maisch., Ber., 23, 1202 (1890).

69. A. Michaelis and F. Kuncke11, Ber., 30, 2827 (1897).

70. D. A, Clibbens and M. Nierenstein, J. Chem。.Soc, 107, $1493^{\circ}(1915)$.

71. F。 Kuncke11 and F. Johannssen, Ber., 30, 1715 (1897).

72. A. Klages and R. Kei1, Ber., 36, 1635 (1903).

73. C. R. No1ler and R. Adams, J. Am.Chem。.Soc., 46, 1893 (1924).

74. H. Ryan, Ber., 31, 2132 (1898)。

75. A. Piutti, Ber., 39, 2771 (1906)。

76. 0. Wallach, Ann., 332, 317 (1904).

77. F. Kuncke11 and R. Zimmermann, Ann., 314, 290 (1901).

78. C. L. Steves, W, Malik and R. Pratt, J. Am. Chem。 Soc., ㄴ, 4758 (1950)。

79. F. C. Whitmore, C. I. No11 and V。C.Meunier,$J_{0}$. Am, Chem。 Soc., 61,684 (1949).

80, R. H, Baker and H. Adkins, J. Am. Chem. Soc。, 62, 3306 (1940). 
81. No Rabjohn and E。 R。 Rogier, Jo Org。Chem。, 11, 781 (1946)。

82. I. J. Krchma and J。.W.Williams, J. Am。 Chem。 Soc., 49, 2413 (1927).

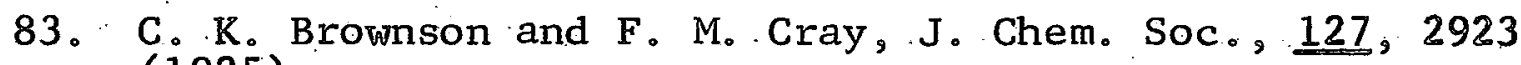
(1925).

84. A. Michaelis and F。Kuncke11, Ber。, 30, 2826 (1897).

85. E。 G。 Edwards, D. P. Evans and H。B. Watson, J. Chem。 Soc。, 1944 (1937).

86. C。.Prẻvost and $Y$ 。 Gaoni, Compt。Rend。, 240, 2244 (1955).

87. $R_{0} R_{\text {。 }}$ Dreisbach and $R$ 。 Martin., Ind。Eng. Chem。, 41,2876 (1949).

88. F. Ho Curd and A. Robinson, J. Chem. Soc, .717 (1933)。

89. No.Rabjohn and E。R.Rogier, J. Org. Chem。, 11, 785 (1946).

90. T. Wo Richards and J.W. Shipley, J.Am. Chem。 Soc., 38, 996 (1916).

91. I。Voge1, J。Chem。.Soc。, 2030 (1928).

92. E。 J。 Corey, J。 Am. Chem. Soc., 75, 2302 (1953).

93. J. $\mathrm{B}_{\circ}$ Rather and E。 M。 Reid, J。 Am, Chem。.Soc, , 41, 77 (1919)。

94. J, H. Boyer and Do. Straw, J。 Am. Chem。 Soc., 74, 4506 (1952)。

95. P..Z. Bedoukian, J. Am。Chem。Soc., 67, 1430 (1945)。

96. B。 Radziszewski, Ber , . 7, .141 (1874)。

97. Jo $F_{\text {}}$. Norris and F. Cortese, Jo: Am。 Chem。. Soc., 49, 2645 (1927).

98. S. M. McElvain, "Characterization of Organic Compounds," Macmillan Co., New York, p. 202 (1958).

99. N.H.Stephens, J。.Am. Chem。Soc, , 50, 189 (1928). 
100. K. Ziegler and P. Tiemann, Ber。, 55, 3414 (1922). 101. R. Quelet, Bul1. Soc。Chim。France, (4), 45, 86 (1929). 102. H. Stobbe and K. Toepfer; Ber, 57, 484 (1924). 103. Fo Eisenlohr and L. Schulz, Ber。, 57, 1811 (1924). 